\title{
TERRITÓRIO E CIDADES NA AMAZÔNIA: UMA LEITURA A PARTIR DAS POLÍTICAS AMBIENTAIS URBANAS
}

\author{
TERRITORY AND CITIES IN THE AMAZON: \\ AN ANALYSIS FROM URBAN ENVIRONMENTAL POLICIES
}

\author{
TERRITORIO Y CIUDADES EN LA AMAZONIA: \\ UN ANÁLISIS DE LAS POLÍTICAS AMBIENTALES URBANAS
}

Adna Alves Abreu ${ }^{1}$ José Queiroz de Miranda Neto ${ }^{2}$

\section{Resumo}

Historicamente, a região amazônica tem sido cenário da implementação de diferentes políticas territoriais, em especial a partir da década de 1960 com a ação desenvolvimentista do Estado e, posteriormente, a partir da década de 1990 com as políticas de ordenamento do território. O objetivo desse trabalho é analisar de que modo as políticas ambientais urbanas foram inseridas nesses diferentes contextos de planejamento $e$ quais os possíveis cenários do quadro ambiental em função de tais ações para as cidades na Amazônia. A metodologia empregada é uma análise bibliográfica de diferentes autores que discutem sobre as políticas de ordenamento territorial, assim como as questões ambientais das cidades. As proposições apontam que não se tem uma política de gestão que atenda as reais necessidades das cidades amazônicas, sobretudo pelos modelos implementados que se pautam sob lógica de desenvolvimento econômico, sem reais ações que visem o bem-estar social e ambiental.

Palavras-chaves: Políticas territoriais, Políticas ambientais urbanas, cidades, Amazônia.

\begin{abstract}
Historically, the Amazon region has been the setting for the implementation of different territorial policies, especially since the 1960s with the developmental action of the State and, subsequently, from the 1990 with land use policies. The objective of this work is to analyze how urban environmental policies were inserted in these different planning contexts and what are the possible scenarios of the environmental framework as a result of such actions for cities in the Amazon. The methodology used is a bibliographic analysis of different authors who discuss territorial planning policies, as well as environmental issues in cities. The propositions point out that there is no management policy that meets the real needs of Amazonian cities, especially by the implemented models that are guided by economic development logic, without real actions that aim at social or environmental well-being.
\end{abstract}

Keywords: Territorial policies, Urban environmental policies, cities, Amazon

\section{Resumen}

Históricamente, la región amazónica ha sido escenario de implementación de diferentes políticas territoriales, especialmente desde la década de 1960 con la acción desarrollista del Estado y,

\footnotetext{
${ }^{1}$ Mestranda em Geografia pelo PPGEO/UFPA. E-mail: adnaabreu16@gmail.com

22E-mail: geoneto@msn.com
} 
posteriormente, desde las décadas de 1990 con políticas de ordenamiento territorial. El objetivo de este trabajo es analizar cómo se insertaron las políticas ambientales urbanas en estos diferentes contextos de planificación y cuáles son los posibles escenarios del marco ambiental debido a tales acciones para las ciudades de la Amazonía. La metodología utilizada es un análisis bibliográfico de diferentes autores que discuten las políticas de ordenamiento territorial, así como la problemática ambiental en las ciudades. Los planteamientos señalan que no existe una política de gestión que satisfaga las necesidades reales de las ciudades amazónicas, especialmente por los modelos implementados que se guían por la lógica del desarrollo económico, sin acciones reales que apunten al bienestar social o ambiental.

Palabras clave: Políticas territoriales, Políticas ambientales urbanas, ciudades, Amazonia.

\section{INTRODUÇÃO}

A necessidade de manter o controle sobre o território por meio de políticas de ordenamento territorial sempre foi uma preocupação dos governos em todo o mundo. Na Amazônia, este cenário se configura de maneira semelhante, uma vez que desde a década de 1960 vêm sendo elaborados programas e projetos que manifestam, cada um à sua maneira, uma perspectiva de integração e desenvolvimento para a região. Verifica-se, entretanto, algumas lacunas sobre como as cidades amazônicas são pensadas no conteúdo desses programas/projetos, assim como os efeitos da aplicação de algumas políticas públicas no território que envolvem a presença das cidades.

Nesse sentido, buscou-se, neste artigo, atender a seguinte problemática em relação as políticas territoriais: de que forma as cidades são comtempladas no tocante às políticas ambientais urbanas e quais os possíveis legados deixados pela implementação de tais ações no quadro ambiental das cidades amazônicas? Para responder a essa questão, foi necessário um diálogo acerca das políticas territoriais em diferentes escalas, fazendo conexões nos âmbitos nacional e internacional para visualizar suas formas de atuação. Cabe ressaltar que muitos elementos desse debate são acrescentados paulatinamente, conforme as determinações cunhadas pelas potências mundiais em nível internacional e absorvidas pelo Brasil, resultando em estratégias primeiramente voltadas à integração nacional, depois à incorporação das políticas ambientais e, por último, ao debate do ordenamento do território.

Devido à abrangência do tema, a metodologia consiste em uma revisão bibliográfica e documental de documentos oficiais de planejamento que abordam sobre as políticas ambientais e territoriais, bem como que auxiliaram numa leitura necessária para contextualização da temática proposta. $\mathrm{O}$ foco de interesse é, então, o das ações institucionais em nível regional, de modo a compreender o conteúdo dos programas/projetos desenvolvidos na Amazônia em cada período delimitado, assim como a visão de diferentes autores sobre as políticas territoriais/ambientais aplicadas, como ênfase na maneira pela qual as cidades foram abordadas. Para além disso, foram utilizados alguns dados secundários do IBGE e do Ministério das Cidades para compor um cenário das políticas direcionadas à região amazônica voltadas à habitação e ao saneamento.

O presente artigo se estrutura em quatro seções. A primeira versa sobre as políticas de desenvolvimento para as cidades e a problemática ambiental urbana, na qual se discute o respectivo papel 
das políticas territoriais quanto ao tratamento da gestão ambiental das cidades. A segunda seção apresenta uma discussão sobre o território e cidades na Amazônia entre 1960 e 1988, de modo a demonstrar como foram introduzidas as intervenções na região Amazônica, sobretudo com base na estratégia geopolítica dos militares. A terceira e última seção, por sua vez, aborda efetivamente sobre as políticas ambientais urbanas para as cidades Amazônicas entre 2001 e 2016, de modo a estabelecer o quadro atual e ambiental vivenciado nas mesmas, manifestando diversas facetas da aplicação de políticas territoriais em contextos urbanos. No presente trabalho, leva-se em conta os processos contraditórios que envolvem agentes como o Estado, as empresas e as populações locais.

\section{AS POLÍTICAS TERRITORIAIS E A PROBLEMÁTICA AMBIENTAL URBANA}

As políticas territoriais, segundo Ruckert (2010, p.18), "são entendidas como o campo das ações emanadas dos poderes centrais, regionais e locais sobre os diversos territórios”. Essas políticas territoriais estão intrinsicamente ligadas às relações de poder, de modo que dentro de uma dimensão multidimensional, os diferentes atores produzem os espaços através de reestruturação dos territórios a partir de novas práticas de poder. Surgem, assim, programas ou modelo de gestão territorial que podem contribuir (ou não) em processos de desenvolvimento endógeno, que atribuiriam novas formas de uso dos territórios.

No presente artigo, faz-se uma leitura das lógicas de organização/planejamento do território a partir do processo de transformações dos espaços urbanos, que culminaram numa perspectiva de implementação de políticas de ordenamento. Entretanto, historicamente esse ordenamento é elaborado com o intuito de integrar os territórios em um nível puramente econômico, sob uma lógica ideológica, de modo que as formas são utilizadas para controle e reprodução do capital em larga escala.

$\mathrm{Na}$ escala do território nacional, o ordenamento territorial se configura sob o:

critério de entendimento da relação da ordem local em uma economia capitalista, com o mecanismo internacional, como a Divisão Territorial do Trabalho dimensiona cada região do globo. E se cada a combinação de variáveis distingue cada lugar ou território, cada período técnico vai por sua vez, direcionar e organizar diferentes paisagens geográficas, dimensionando funções e estruturas especificas, além de formas e os processos de acordo com cada função produtiva do território. (CAMARGO, 2009, p. 29).

Assim, podemos destacar em relação as políticas de ordenamento do território como processos que assumem relevo conforme diferentes propósitos, em distintas realidades espaço-temporais. Na escala mundial, há uma preocupação frente a grande competitividade das economias, principalmente nos países da Europa. A estratégia da União Européia reflete essa postura em face aos desafios da nova ordem mundial, sugerindo um trade-off ${ }^{\beta}$ entre crescimento econômico e equilíbrio ambiental, devendo-se, em certa medida,

\footnotetext{
${ }^{3}$ A expressão trade-off é utilizada na economia para se referir aos "custos de oportunidade", quando o indivíduo, uma empresa ou, mesmo, um país deixa de usufruir de uma coisa por ter escolhido outra.
} 
Território e cidade na Amazônia:

Uma leitura a partir das políticas ambientais urbanas

sacrificar o último em função do primeiro. Dessa forma, o foco não é promover um equilíbrio regional, mas atrelar os usos dos recursos aos países e regiões mais providas de condições (PORTO, 1996). Nessa lógica, as políticas territoriais oscilam entre uma orientação que assume como principal objetivo o crescimento econômico, prevendo compensações sociais para os segmentos não beneficiados por esse crescimento. Em geral, os discursos procuram associar crescimento econômico e redução das desigualdades (BITOUN; MIRANDA, 2009).

Ainda sobre o contexto da União Europeia, Ruckert (2010, p. 22) afirma que:

O Novo Regionalismo tem sido a abordagem que tem inspirado a perspectiva territorial e a política regional da UE. Para enfrentar o desafio de construir um cenário de competitividade e coesão-social e territorial sob os paradigmas do conhecimento e da inovação, as políticas da EU capitalizaram a nova onda de regionalismo fortalecida na Europa desde os anos 1980.

Nesta perspectiva, Fonseca (2004) aponta uma discussão sobre a política regional da União Europeia, que perpetua um modelo que se organiza em três pilares fundamentais: o crescimento econômico, a estabilidade e a coesão, de modo que o principal objetivo da Política Regional se inscreve no pilar da coesão. Tal modo de pensar a política territorial expressa o ideário social-democrata europeu, ainda bem evidente na década de 1980, com estratégias de gestão integrada que reflete os interesses desses países em processo avançado de união econômica e monetária, incluindo políticas ambientais comuns.

É importante percebermos que, atualmente, com todas as mudanças aconteceram no mundo com processo de urbanização, principalmente nos países em desenvolvimento na última metade do século passado, resultou em grandes concentrações populacionais em um número reduzido de cidades (BOARETO, 2008). Como salienta Camargo (2008, p.21) "o espaço encontra-se mais interconectado e preenchido por inúmeras possiblidades", contudo, como esse processo implica no ordenamento dos territórios, deve-se ter o cuidado quanto aos modelos que irão disciplinar a sociedade de maneira que estes não lhe custem a liberdade.

Isto corrobora com o que discute Boareto (2008, p. 145) ao afirmar que "o processo de urbanização em curso propicia a fragmentação do espaço urbano, criando bairros residenciais cada vez mais distantes dos locais de trabalho e de lazer, além de expulsar a população mais carente para a periferia dos grandes centros. Dentro desse panorama, a leitura sobre os espaços urbanos, sobretudo na sociedade contemporânea, retratase a partir de conflitos e contradições, onde o planejamento urbano se mostra incapaz de conter os problemas sociais das cidades, alicerçado a uma estrutura que reflete na insuficiência de provimento de serviços básicos, o que acaba resultando numa decadência profunda no espaço urbano (BARBOSA, 2006).

Nessa perspectiva, o modo de reduzir parte desses problemas relacionados a cidade, é a partir ao fortalecimento do papel das políticas públicas urbanas, segundo Théry (2011, p. 12) "pela demanda de reestruturação do espaço e o reordenamento do território em face à atual fragmentação das cidades”. Diante 


\section{Território e cidade na Amazônia:}

\section{Uma leitura a partir das políticas ambientais urbanas}

de tais proposições, podemos visualizar ações ou políticas territoriais de ordenamento e gestão de cidades, como em Portugal, cuja gestão se organiza em função dos modelos da União Europeia, pautada sobretudo em uma lógica fundamentada nas relações mundiais de comércio.

São essas relações que moldam e articulam políticas que incluem a atuação de diferentes atores sociais para implementação de políticas de ordenamento do território, marcada pela configuração de planos de desenvolvimentos ou metas. No caso do Brasil, os planos de desenvolvimento instituíram uma concepção cujo escopo era construir um país que atua em coesão entre as próprias elites, ao se estabelecer um projeto nacional comum. Tal concepção desconsidera que a construção de um projeto territorial faz parte de uma obra de interesse geral, que inclusive se sobrepõem a projetos locais e regionais. Além disso, como sugere Moraes (2005), a construção do país é conduzida pela ação legitimada do Estado, o qual por vezes se utiliza de seus traços autoritários para a realização de seus projetos de desenvolvimento.

A discussão sobre as políticas ambientais no Brasil é de origem recente, como salienta Peccatiello (2011, p. 73) "a política ambiental no Brasil se desenvolveu em resposta às exigências do movimento internacional ambientalista iniciado a partir da segunda metade do século XX, durante a década de 1960". Os diversos ciclos econômicos foram, de certa forma, "desastres ecológicos", pois a cada fase de intensa exploração e prosperidade seguiu-se outra de estagnação e decadência. Em meados do século XX se tem, de forma tímida, a implementação de políticas públicas que podemos destacar como um start para se pensar as questões ambientais. Contudo, como destaca Silva; Travassos (2008, p. 28) "especialmente no Brasil, podese dizer que a institucionalização da questão ambiental urbana não apresentou reflexos concretos nas cidades".

Desde a década de 1950, como aponta Costa (1991), as políticas econômicas formuladas pelo Estado passaram a ser integradas a macroplanos de desenvolvimento, no qual as questões setoriais e regionais passaram a ser integradas a uma estratégia extensível a todo o país. Começa, então, a implementação de vários planos para corrigir as "disparidades regionais", como o plano trienal (1962), o Programa de Ação Econômica do governo (PAEG) nos anos de 1964, o Plano Decenal de Desenvolvimento Econômico e social (1967-1976) e o Programa estratégico do Governo (1968-1970). Até esse ponto, os planos privilegiavam a necessidade de integração nacional, instruídos sob a insígnia do "Brasil grande" dos militares

Na década de 1970, o principal plano geral foi o Plano de Desenvolvimento Econômico Social (I PND-I), que tem por base o Programa de Integração Nacional (PIN). Tais programas acentuavam a tendência de expansão da "fronteira econômica" do país que partia do Centro-Sul, na direção do Centro-Oeste, Amazônia e Nordeste. Em 1972 é editado o II PND, tendo este uma dimensão focada na tentativa de um incentivar o crescimento econômico de setores ligados às exportações. Para alcançar essa meta, privilegiamse os empreendimentos da fase monopolista do capitalismo, a partir de capitais privados, nacionais e 


\section{Território e cidade na Amazônia:}

\section{Uma leitura a partir das políticas ambientais urbanas}

estrangeiros, além de investimentos em infraestrutura (COSTA, 1991). Os programas criados para atender essas finalidades, como POLOAMAZÔNIA e POLO-CENTRO, serão explicitados mais adiante.

Essa visão também está interligada às políticas territoriais para Amazônia, vista como fonte de recurso a ser utilizado para dinamizar as relações que antes eram poucos interligadas economicamente. A partir dos apontamentos de Peccatiello (2011), considera-se a evolução das políticas ambientais no Brasil como forma de demonstrar que, apesar de nem todas as ações se manifestarem concretamente, houve marcos importantes acerca da conservação dos recursos naturais. Peccatiello (2011, p. 73-74) se fundamenta em várias abordagens até a constituição de 1988, que são apresentadas a seguir, de modo sintético:

a) a primeira abordagem nos anos 1930, caracterizada pela regulamentação da apropriação de cada recurso natural em âmbito nacional, com foco nas necessidades da nascente industrialização e urbanização;

b) a segunda abordagem, baseada no controle da poluição industrial, ganhou força a partir da década de 1970, influenciada principalmente pela Conferência das Nações Unidas sobre Meio Ambiente, realizada em 1972, em Estocolmo. Essa etapa é caracterizada por uma urbanização intensa e por um crescimento acentuado das regiões metropolitanas;

c) a terceira fase, iniciada em 1981, foi marcada pela "gestão integrada de recursos", com a formulação da Política Nacional de Meio Ambiente (Lei n 6.938 de 31/08/81, regulamentada em 1983) e o Ministério de Desenvolvimento Urbano e Meio Ambiente, em 1985, o qual tem por funções a definição das políticas e a coordenação das atividades governamentais na área ambiental.

Com a constituição de 1988, se tem uma preocupação maior com as questões urbanas e sua relação ao meio ambiente. Um dos exemplos é a maior participação dos municípios no processo de planejamento territorial, com a responsabilidade de implementação de um plano diretor de cidades com mais de 20.000 habitantes. Acontece, igualmente, a exigência de estudos sobre os impactos de possíveis obras ou atividades poluidoras. Assim, assumia-se um posicionamento mais consistente no que tange ao fortalecimento de instrumentos para melhor gestão das questões ambientais no Brasil.

Essa mudança de orientação ocorre por conta de intervenções em nível internacional, como a que resultou no relatório de Brutland, mais conhecido como "Nosso futuro comum", em 1987, com participação de várias organizações internacionais para discutir sobre o desenvolvimento sustentável. Em 1992, a discussão sobre a problemática ambiental cresce com a Conferência das Nações Unidas para o Meio Ambiente - UNCED (também conhecida como Cúpula da Terra, Eco-92 e Rio-92), realizada na cidade do Rio de Janeiro, onde se reuniram representantes de 175 países e de organizações não governamentais (PECCATIELLO (2011).

Nesse mesmo cenário são implementadas as políticas ambientais, como aponta Moraes (2005, p. 143):

De modo a contribuir para um momento de ações sobre as pressões sofridas pela natureza, surge uma nova faceta das políticas ambientais no Brasil, sobretudo a partir de 1988, quando se cria o Instituto Brasileiro de Meio Ambiente e dos Recursos Naturais 


\title{
Território e cidade na Amazônia:
}

\section{Uma leitura a partir das políticas ambientais urbanas}

\begin{abstract}
Renováveis (IBAMA). Essa política simboliza, juntamente com criação de vários órgãos e institutos federais, como o Instituto Brasileiro Desenvolvimento Florestal (IBDF), uma nova visão acerca das questões ambientais no Brasil, cujo eixo norteador se permeia dentro de uma discussão baseada na temática do "desenvolvimento sustentável". Contudo, essa perspectiva encontra muitos obstáculos, pois pauta-se no resgate da discussão mais próxima do planejamento participativo, descentralizado, em controvérsia do modelo tradicional implementados historicamente no Brasil, marcado por políticas autoritárias e centralizadoras.
\end{abstract}

Isso decorre do poder de um discurso que estabeleceu diretrizes ambientais no que tange a uma melhor gestão dos problemas, entretanto, a realidade que envolve as cidades brasileiras se apresenta de forma complexa. Há outros desafios no espaço urbano que dizem respeito à incapacidade de promover ações articuladas que levem em conta não só a degradação causada ao meio ambiente, mas consiga relacionar isto à forma pelo qual se produziu o espaço. A situação é que fica difícil os equacionamentos dos problemas quando se encontra tantos passivos para se prosseguir, sendo isso no Brasil uma realidade comum (SILVA; TRAVASSOS, 2008).

No início da década de 2000, sob forte influência dos acordos internacionais, se tem a implementação políticas públicas a fim de diminuir os problemas de cunho ambiental nas décadas anteriores, como o desmatamento, problemas ligados ao saneamento, dentre outros que afetam tanto os diferentes biomas brasileiros como o espaço das cidades. A respeito disso, para que haja então uma melhor forma de gestão dos territórios, foram implementadas políticas para as cidades, como o Estatuto da Cidade, implementada pela criação da lei 10. 257, de 10 de julho de 2001, que determina:

I - Garantia do direito a cidades sustentáveis, entendido como o direito à terra urbana, à moradia, ao saneamento ambiental, à infraestrutura urbana, ao transporte e aos serviços públicos, ao trabalho e ao lazer, para as presentes e futuras gerações;

II - Gestão democrática por meio da participação da população e de associações representativas dos vários segmentos da comunidade na formulação, execução e acompanhamento de planos, programas e projetos de desenvolvimento urbano;

III - cooperação entre os governos, a iniciativa privada e os demais setores da sociedade no processo de urbanização, em atendimento ao interesse social;

IV - Planejamento do desenvolvimento das cidades, da distribuição espacial da população e das atividades econômicas do Município e do território sob sua área de influência, de modo a evitar e corrigir as distorções do crescimento urbano e seus efeitos negativos sobre o meio ambiente.

$\mathrm{V}$ - Oferta de equipamentos urbanos e comunitários, transporte e serviços públicos adequados aos interesses e necessidades da população e às características locais. (PLANALTO, 2020)

Com o Estatuto da Cidade, pode-se dizer que, pela primeira vez, se tem um conjunto normativo especialmente direcionado às questões ambientais urbanas, referindo-se à esfera de direitos que antes não 


\section{Território e cidade na Amazônia:}

\section{Uma leitura a partir das políticas ambientais urbanas}

eram bem definidos em marcos legais anteriores. Porém, o que se observa é um processo bem mais complexo, já que as cidades apresentam grandes problemas relacionados aos serviços mais básicos, como o saneamento básico. Fica evidente que ainda há uma distância considerável entre o que é estabelecido pela lei e o que, de fato, se concretiza nas cidades. Se faz preciso, portanto, um diálogo sobre as políticas ambientais urbanas de forma a considerar a realidade enfrentada pelas cidades, principalmente em espaços historicamente excluídos do ponto de vista da qualidade de vida urbana, como na região amazônica.

No caso amazônico, podemos mencionar a cidade de Manaus, capital do Amazonas, como sendo um exemplo de área urbana no meio da floresta que atualmente tem enfrentado um preço ambiental muito alto por conta de sua expansão urbana dos últimos vinte anos. O modelo de desenvolvimento urbano excludente é a estruturação de arranjos urbanos marcados por um "mosaico" de paisagens reveladoras e geradoras da segregação socioespacial (NOGUEIRA; SANSON; PESSOA, 2007). Desse modo, apesar de todas as inciativas apontadas até aqui e dos relativos avanços na temática ambiental para as cidades, o discurso de um desenvolvimento sustentável capaz de reduzir as limitações ambientais e melhorar a qualidade de vida nos territórios "integrados" nacionalmente não ocorre de fato. Apresentaremos posteriormente as políticas territoriais no cenário amazônico, com as proposições nos diferentes marcos que construíram estruturas nesta região.

\section{TERRITÓRIO E CIDADES NA AMAZÔNIA ENTRE 1960 E 1988}

A Amazônia legal se configura como um território que, até 1970, era desprovido de muitas conexões com o restante do país, sendo as políticas de ocupação combinadas a empreendimentos de exploração econômica. Em princípio, o Estado se valeu de estratégias geopolíticas, baseadas em ações militares impulsionadas por um duplo objetivo: "a preservação das fronteiras internacionais e a “incorporação de sua economia ao todo nacional” (COSTA, 1991).

Becker (2006) apresenta a Amazônia como uma economia de fronteira de recursos e ressalta três características que são de fundamental importância para percepção das relações complexas no que tange a temática ambiental discutida sobre o cenário amazônico, sobretudo nas décadas de 1960/1970: a) a abertura de estradas e das rede de telecomunicação que promoveram uma nova conexão em escala internacional; b) a mudança da economia baseada no extrativismo para uma lógica de capital baseada na indústria moderna; e c) uma mudança organizacional da sociedade que ocorreu sobretudo em função da urbanização, no qual o povoamento não acontece nas margens do rio, mas sim ao longo das estradas.

Nesse contexto, as políticas desenvolvimentistas direcionadas à Amazônia encontram um terreno fértil. Como aponta Moraes (2005, p. 94-95) trata-se da "elaboração de discursos legitimadores onde o país é visto como um espaço a ser conquistado e ocupado". A ocupação efetiva se configura com o plano de metas da década de 1960 e na construção de rodovias como a Transamazônica (BR 230). Como resultados, houve um processo de ocupação intenso na Amazônia Oriental que, articulada ao novo eixo rodoviário, intensificou 
suas atividades econômicas nas décadas de 1960 e 1970, em princípio com a atividade de assentamentos agrícolas conduzidos pelo INCRA e, posteriormente, com base na pecuária de corte e na mineração.

Entre 1974 e 1979, houve a implantação do Polamazônia, que foi uma estratégia de planejamento que utilizou o conceito de polos econômicos como destaca Kohlhepp (2002, p. 39) "baseados em pontos focais setoriais separados como, por exemplo, extração de recursos minerais ou áreas de criação de gado com possível processo industrial”. Essa forma de planejamento regional, resultou num cenário que incentivou grandes investidores nacionais e internacionais a partir de taxas tributarias baixas a exploração de terras muito acentuada. Assim, com o aumento da exploração dos recursos, se condiciona a natureza a um status de maior fragilidade, posto que o aumento de atividades econômicas como a pecuária, o incentivo para programas mineradores, o aumento da atividade madeireira, implica em um cenário de grandes impactos sobre o meio ambiental.

Em função dessas ações visando prioritariamente o crescimento econômico, a Amazônia Legal se torna um campo de enfrentamentos relacionado as disputas por frações do território que envolvem posseiros, grileiros, madeireiros, populações indígenas, pescadores, e outros agentes. Essas mudanças também são percebidas nas cidades, já que acabam sendo não apenas pontos de referência, mas verdadeiros suportes logísticos, denominados "Núcleos de Apoio ao Processo de Ocupação", como Marabá, Tucuruí, Santarém, Altamira, Oriximiná e Itaituba, como se identifica na Figura 1.

Figura 1 - Núcleos de Apoio à Ocupação no II PND

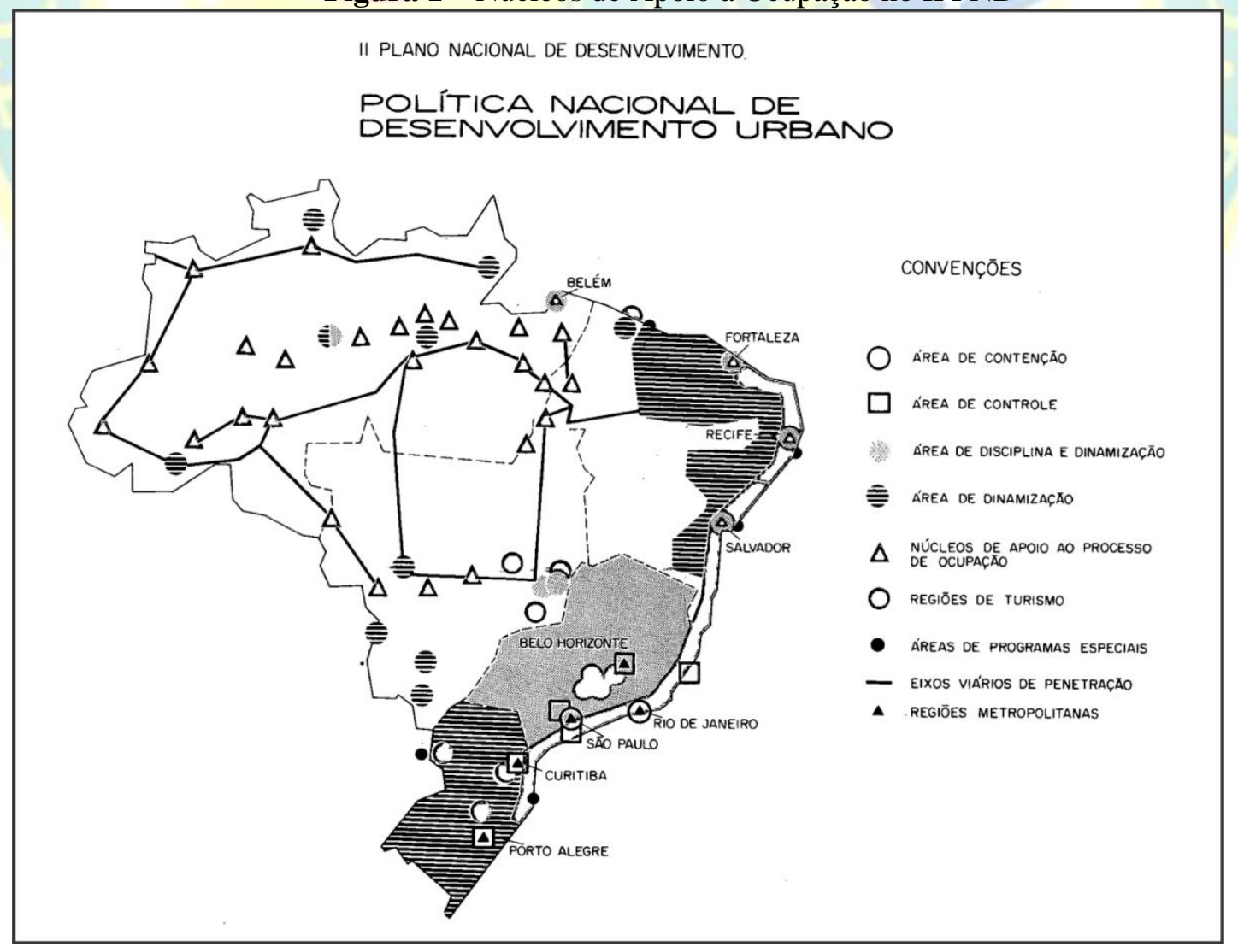

Revista do Instituto Histórico e Geográfico do Pará (IHGP), (ISSN: 2359-0831 - on line), Belém, v. 08, n. 01, p. 230 - 248, jan.jun. / 2021. 


\section{Território e cidade na Amazônia:}

\section{Uma leitura a partir das políticas ambientais urbanas}

Fonte: BRASIL. II Plano de Nacional de Desenvolvimento (1975-1979), Brasília, 1974.

Podemos destacar que são muitos os problemas resultantes dos planos de desenvolvimento para a Amazônia, mantendo-se o viés de apropriação de exploração de seus recursos, com políticas que privilegia desenvolvimento econômico. Muito embora tais projetos abordem a questão da qualidade de vida, os problemas decorrentes dessa política foram bem evidentes na primeira fase da ditadura militar como aponta Costa (1991):

A ocupação baseada em grandes projetos agropecuários e agroindustriais[..] tem sido responsável pela maior parte dos problemas ecológicos[..] Polo industrias como Manaus e Belém, se por um lado atraíram industriais, por outro, provocaram distorções de toda ordem nesses centro urbanos,[..] como desemprego, ao lado do subemprego,[..] também as vias de circulação que contribuíram para a invasão nas terras indígenas desequilibraram a economia de subsistência e facilitaram o surgimento de núcleos urbanos sem qualquer planejamento.

Pode-se perceber que as políticas de ordenamento do território sempre estão atreladas a um campo de forças complexo, que se renovam e ressignificam conforme o viés político-econômico do Estado e dos agentes privados. No tempo do governo militar, as estratégias previam a ocupação pelo modelo geopolítico que desconsideravam questões que, pelo menos até a década de 1970, não estavam bem articuladas em nível global, como a proteção ambiental e a preservação. Aqui, as cidades são pouco destacadas em seu aspecto interno, suas funções e formas de se promover o crescimento. São entendidas, entretanto, como suporte às atividades do campo, como centros logísticos ou polos para o desenvolvimento econômico. Ao contrário do proposto, entre 1965 e 1988 as cidades passaram a absorver a população mais pobre que não conseguiu se manter no campo, gerando contradições internas que são objetivadas na ausência de saneamento e a ocupação de terras em áreas improprias.

\section{AS POLÍTICAS TERRITORIAIS E AS CIDADES AMAZÔNICAS: O CENÁRIO DE 2001 A 2016}

A Amazônia passou por mudanças estruturais que possibilitaram a configuração de diferentes cenários quanto às políticas ambientais geradas pelas estratégias territoriais anteriores. Vale ressaltar o papel das lutas sociais, do processo de urbanização e de diferentes formas organização da sociedade propondo projetos alternativos. Considerando as características naturais da Amazônia e sua importante biodiversidade, manifesta-se um quadro de muitos conflitos. Esse campo de forças inclui a disputa dos agentes na tentativa de estabelecer o uso predatório de diferentes frações desse território, no mesmo passo em que alguns movimentos sociais e populações tradicionais atuam na tentativa de manter sua preservação.

No que tange às políticas ambientais para a Amazônia nesse período, se destaca a ação de programas como Programa Piloto Internacional para Conservação das Florestas Tropicais Brasileiras (PPG7). O programa buscava, juntamente com outros projetos, auxiliar no uso dos recursos naturais baseados no princípio da sustentabilidade, com intuito de reduzir as taxas de desfloramentos e manter a biodiversidade na Amazônia. Contudo, desde a implementação, na primeira metade de 1990, as atividades se desenvolveram na 


\section{Uma leitura a partir das políticas ambientais urbanas}

Amazônia de forma desigual, isto porque de um lado havia incentivos do governo para a melhoria da infraestrutura e integração ao mercado e, de outro, o compromisso do programa em realizar o desenvolvimento sustentável. Segundo Aquino (2009, p. 233) o PPG-7

veio a existir dado interesse dos Países do G-7 em apoiar ações que maximizassem os benefícios ambientais das florestas tropicais de modo adequado ao desenvolvimento do Brasil. Então, uma comissão de ministros do governo brasileiro, Banco Mundial e a Comunidade Europeia, cientes desse interesse, elaboraram três encontros (dez/90Washington; Bruxelas-mar/91 e Rio-mai/91), uma proposta de programa.[..] Para a primeira fase de execução do programas, ficou acordado um volume de recursos de ordem de US\$ 250 milhões, 10\% financiado pelo governo Brasileiro.

Apesar dos problemas, o programa avançou no sentido de ser o meio condutor de projetos mais consistentes com a proteção ambiental, com políticas descentralizadas que envolveram as principais pautas das reivindicações sociais e colaboram para algumas conquistas. Houve, assim, o fortalecimento de projetos alternativos que possibilitaram um novo padrão para a Amazônia, segundo Becker (2010a):

A demarcação de Terras Indígenas, uma conquista dos direitos coletivos das comunidades indígenas, que começou a ser aceita pelo governo em 1991 e tem resultado na demarcação de seus territórios e fortalecido seu papel como atores políticos no cenário regional. Entre 1995 e 1998, o governo reconheceu 58 Reservas Indígenas, correspondendo a 26 milhões de ha, e demarcou 115 , equivalendo a $311.000 \mathrm{~km} 2$, de modo que $63 \%$ das terras indígenas estão hoje demarcadas, representando $78 \%$ da área total de reservas nacionais. as áreas protegidas se referem às Unidades de Conservação (UCs), de vários tipos, que se multiplicaram na Amazônia a partir de meados de 1980. [..] às áreas protegidas relações estreitas com a União, através da Funai e do Ibama. Dentre elas, destacam-se as Reservas Extrativistas (Resex), fruto da luta dos seringueiros por sua sobrevivência na floresta, contra a expansão dos fazendeiros de gado e os projetos de colonização do Incra.[..] Projetos alternativos[..]A gestão dos PDA também é variada, nela tendo grande influência as redes sociais de igrejas e ONGs internacionais, e relativamente menor influência nas relações com o governo. A experiência de pequenos produtores melhor sucedida é o Projeto Reflorestamento Econômico Consorciado Adensado (RECA), localizado na fronteira entre o Acre e Rondônia. A mais recente e audaciosa proposta de modelo endógeno (1996), é a dos Corredores de Conservação ou Ecológicos, que correspondem a uma revolução no planejamento em conservação. (BECKER, 2010a, p.146-147)

Em relação a proteção do meio ambiente, o Zoneamento Ecológico-econômico (ZEE) foi um componente que se configurou crucial para se entender o território, contribuindo com a integração de políticas públicas como mecanismo para o melhor planejamento dos espaços (BECKER, 2010a). Houve, nesse caso, um conjunto de instrumentos jurídico-políticos que considerou os modelos já implementados na Amazônia, combinado às novas políticas de viés mais voltado à proposta de desenvolvimento sustentável. Tais ações se deram de modo articulado ao componente sociedade civil, incluindo movimentos sociais e ambientais para a preservação dos recursos naturais e garantia dos territórios das populações tradicionais da Amazônia.

Entende-se que as políticas de ordenamento do território ganharam uma nova roupagem após o Governo de Luiz Inácio Lula da Silva (2003-2010), quando se evidenciam mudanças mais expressivas 
quanto ao viés das políticas territoriais, como afirma Silva e Borges (2014) com ênfase em políticas sociais mais fortalecidas, com a implementação de programas como Programa de Aceleração do Crescimento (PAC), assim como a criação da Política Nacional de Desenvolvimento Regional (PNDR), de modo a se pensar em uma gestão sobre o território mais eficiente e integrada.

Nesse sentido, entretanto Silva; Borges (2014, p.1362) afirmam:

Apesar dos avanços incorporados pela PNDR, ela ainda apresenta significativas limitações nas dimensões teórica, operacional e política [..] das limitações teóricas ressaltam-se: a ênfase nos paradigmas da industrialização, da infraestrutura econômica e do desenvolvimento local; a fraca associação entre planejamento regional e urbano; o déficit de análises críticas no âmbito das políticas regionais acerca das implicações do turismo e do agronegócio enquanto vias para a promoção do desenvolvimento socioeconômico. Dentre as limitações operacionais apresentadas pela PNDR, destacam-se: a problemática da revisão dos recortes regionais; a falta de mecanismos que promovam a organização e o planejamento nos recortes regionais estabelecidos; e, a problemática da assimetria entre as regiões e entre os entes federados. No âmbito das limitações políticas a perda de importância da questão regional ao longo dos governos de Luís Inácio Lula da Silva e Dilma Rousseff têm prejudicado a consolidação e a implementação da PNDR, pois, embora a questão regional sido reinserida na agenda governamental ela nunca ganhou prioridade dentre as políticas públicas.

Políticas como a PNDR e as agendas sociais representadas por programas como Territórios da Cidadania e pelo Programa Bolsa Família, atuaram em regiões diversificadas, com particularidades especificas, forçando novas formas de gerir espaços, com um olhar sobre diferentes escalas (SILVA; BORGES, 2014). Pela primeira vez, se tem um conjunto mais amplo de políticas federais voltadas diretamente aos problemas urbanos, que passaram a ser campo de responsabilidade direta do Ministério das Cidades, criado em 2003. Segundo Maricato (2006, p. 215) “o Ministério das Cidades tem sua criação, portanto, ligada a esse movimento social urbano que teve início ainda nos anos 1970 e que acumulou forças nas duas décadas seguintes na luta pela democratização do país e pela reforma urbana".

Durante a constituição desses novos marcos legais e institucionais, deve-se considerar a importância da Política Nacional de Desenvolvimento Urbano (PNDU), que toma como diretrizes os fundamentos presentes no Estatuto da Cidade (lei 10. 257, de 10 de julho de 2001), visando, dentre outros elementos: a) a Política de Apoio à Elaboração e Revisão de Planos Diretores; b) Política Nacional de Apoio à Regularização Fundiária Sustentável; c) a Política Nacional de Prevenção de Risco em Assentamentos Precários; d) a Política Nacional de Apoio à Reabilitação de Centros Urbanos (BRASIL, 2004). Pela primeira vez se tem um conjunto macro de ações ambientais relacionadas aos centros urbanos, como o acesso ao saneamento e prevenção de riscos, que passam a ser consideradas como política integrada, como afirma o documento base da PNDU:

O reordenamento institucional dos serviços de saneamento ambiental se dará pela instituição de um Sistema Nacional de Saneamento Ambiental, no qual a participação dos entes federados ocorrerá por adesão voluntária expressa, por meio de ato ou declaração de vontade, ou tácita, mediante o recebimento pelo titular ou prestador de serviço público de recursos ou fundos da União. Desta forma, e sem infringir as competências e titularidades definidas constitucionalmente, a adesão ao Sistema Nacional de Saneamento Ambiental 


\section{Território e cidade na Amazônia:}

\section{Uma leitura a partir das políticas ambientais urbanas}

instituirá em cada município ou consórcio público o sistema de fundos de universalização de saneamento ambiental, que serão instrumentos transparentes para operações de crédito e para a gestão de recursos provenientes de dotações orçamentárias, subvenções, contribuições legais públicas ou privadas e subsídios cruzados externos (BRASIL, 2004).

Uma das principais críticas aos programas ambientais voltados às cidades no período anterior era a ausência de participação social e de ações mais articuladas entre os entes federais, estados e município. O ministério das cidades e o PNDU vieram suprir essa lacuna, sugerindo um modelo de ação diferente, como afirma Maricato (2006):

A criação do Ministério das Cidades e o processo de formulação da PNDU, com participação social, tende a ser um forte impulso para incluir a questão urbana na agenda política brasileira. O Ministério das Cidades articula transversalmente a questão financeira e fundiária buscando definir políticas gerais e setoriais integradas - habitação, saneamento ambiental e transportes - para as cidades, sem desconhecer as competências municipais e estaduais. A Política Nacional de Habitação articula terra e financiamento sendo, portanto, dependente da cooperação entre diferentes esferas da federação (MARICATO, 2006, p. 2019).

Uma mudança perceptível em relação às políticas ambientais anteriores se refere à efetivação de muitos programas propostos com recursos do PAC e investimentos diretos do Governo em Lei Orçamentária Anual (LOA). No ano de 2004 foram destinados 3,6 bilhões na LOA para o saneamento básico. Em 2013, esses valores foram multiplicados em quase 5 vezes, passando para 14,83 bilhões, em valores deflacionados (BRASIL, 2013). Entretanto, apesar dos investimentos realizados ao longo da década de 2010, percebe-se, ainda, um quadro bastante negativo quanto ao saneamento básico nas cidades Amazônicas. O Mapa 1 apresenta os dados do Censo 2010 relativo ao quantitativo de domicílios particulares permanentes sem banheiro e sem sanitário, dado é revelador da ausência ou da precariedade de saneamento nos municípios brasileiros das regiões Norte e Nordeste.

Ainda no que se refere ao saneamento, entre 2005 e 2015 quase todas as regiões do Brasil verificaram redução de déficit relativo de acesso a água. A exceção foi a região norte do país, onde houve aumento de déficit relativo de 5,0 pontos percentuais ${ }^{4}$ nesse período, de acordo com o relatório do Instituto Trata Brasil (2015). Segundo dados do mesmo instituto, houve uma redução no déficit de saneamento relacionado ao tratamento de esgoto de $-4,0 \%$ entre 2005 e 2015 , porém esta redução foi a menor entre as regiões se comparado ao Nordeste $(-6,3 \%)$, ao Sudeste $(-13,8 \%)$, ao Sul $(-13,8 \%)$ e ao Centro-oeste ($11,4 \%)$. Isso significa que, apesar das políticas e do aumento do investimento, houve dificuldades para se reduzir os problemas de saneamento nas cidades amazônicas (TRATA BRASIL, 2017). No último ranking do Saneamento Básico, realizado com as 100 maiores cidades do país, figuram entre seis últimas (com o pior saneamento) as cidades de Belém (PA), Manaus (AM), Santarém (PA), Porto velho (RO), Macapá (AP) e Ananindeua (PA), respectivamente (INSTITUTO TRATA BRASIL, 2020).

\footnotetext{
${ }^{4}$ Esse aumento é um dado negativo, pois significa que menos pessoas tem acesso à água tratada nessa região. 


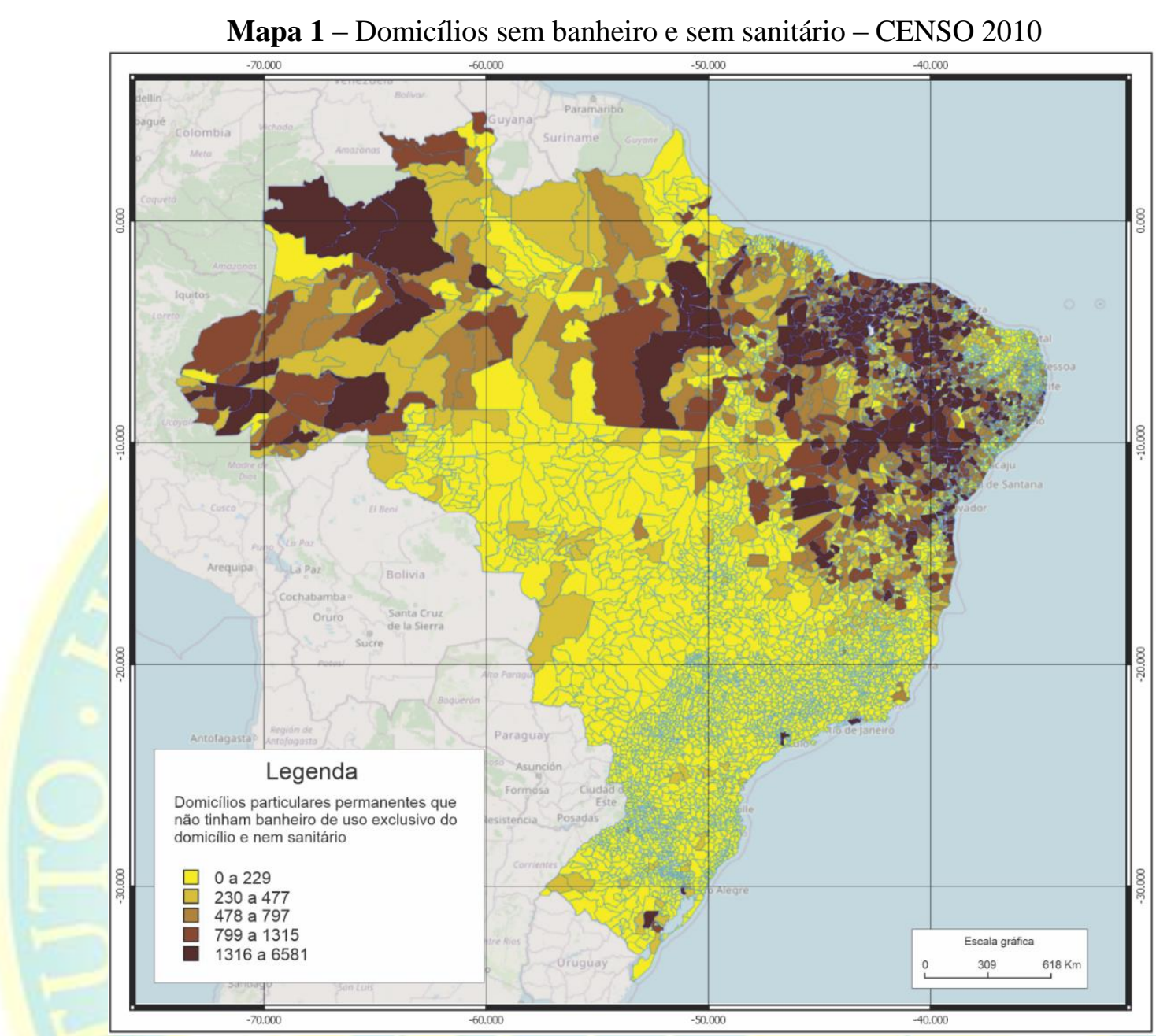

Fonte: CENSO 2010 (IBGE) disponível em: https://censo2010.ibge.gov.br/entorno/

Em parte, essa desigualdade seria superada por conta do novo programa de habitação relacionado ao PNDU, que foi dividido em dois subsistemas: o subsistema de mercado e o subsistema de interesse social (BRASIL, 2004). Segundo Maricato (2006) a estratégia seria "combinar ações que ampliem o mercado privado em direção às classes médias que atualmente não encontram alternativas para sua moradia e ações de promoção pública que deem conta da população de rendas mais baixas” (MARICATO, 2006, p. 217). Ainda no Governo Lula foi criado o Programa Minha Casa Minha Vida (PMCMV), que representou um verdadeiro marco das políticas habitacionais no Brasil, com oferta de milhares de residência em diferentes faixas de renda. Considerando o período entre 2009 e 2012, foram ofertadas 298 mil unidades habitacionais nos estados amazônicos 5 , somando mais de 14 bilhões em investimentos, considerando apenas os empreendimentos de faixa 1, com renda até 1800 reais (MINISTÉRIO DAS CIDADES, 2012).

\footnotetext{
${ }^{5}$ Para efeito de comparação com o território da Amazônia Legal, considera-se todos os estados da região Norte mais os estados do Matogrosso e Maranhão. 
Território e cidade na Amazônia:

Uma leitura a partir das políticas ambientais urbanas

Comparados aos dados nacionais, entretanto, percebe-se uma diferença regional importante, com destaque aos estados de São Paulo, Bahia, Rio de Janeiro, Minas Gerais e Pará, que estão entre os cinco com maior valor em investimentos destinados à faixa 1 .

Gráfico 1 - Número de Empreendimento e valores de investimento do PMCMV até 2012

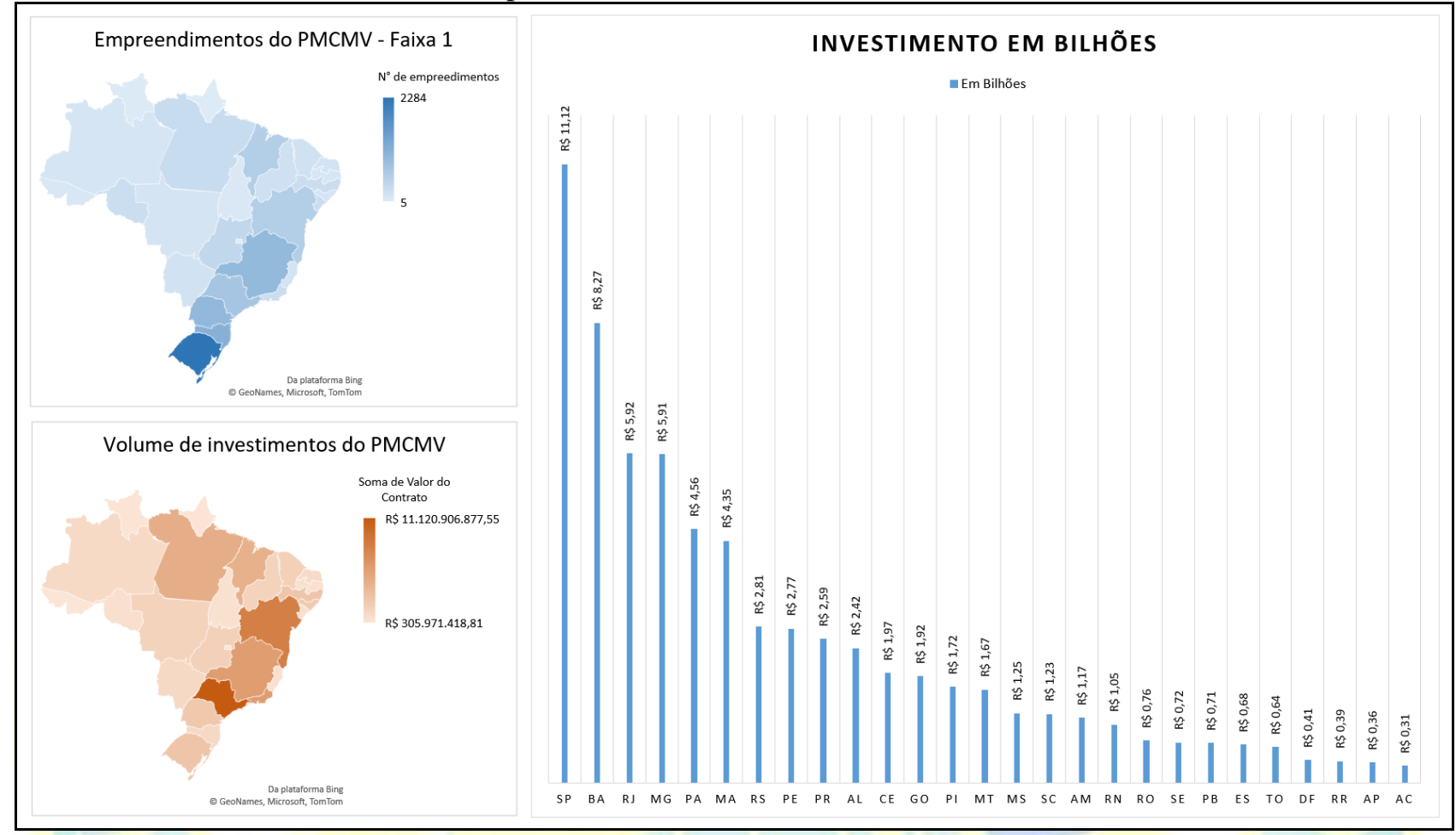

Fonte: Ministério das Cidades, 2012.

Houve, portanto, um avanço expressivo das políticas voltadas à habitação de interesse social, com destaque ao PMCMV, que foi importante no que se refere ao acesso as condições ambientais menos insalubres no ambiente urbano por conta da situação de inadequação da moradia, quanto à redução do déficit habitacional. Esse modelo só foi possível, entretanto, a partir da articulação regional e da relação entre o Estado e o mercado no processo de produção e venda de moradia para a população mais pobre. Considera-se que estas políticas estão mais próximas do que propõe o modelo de ordenamento territorial desenvolvidas no início desse artigo, baseadas nos princípios de coesão entre o crescimento econômico e a estabilidade entre as regiões, tal como designou Fonseca (2004).

Em suma, todos os programas e tendências das políticas que envolvem a questão ambiental na Amazônia ainda encontram muitos percalços a serem superados para conseguirem, de forma efetiva, mitigar os impactos da desigualdade regional histórica e das atividades econômicas predatórias. Nota-se, diante disso, um debate ainda pouco desenvolvido sobre o papel das cidades na questão ambiental na Amazônia, mesmo nos projetos provenientes dos governos Lula (2004-2010) e Dilma (2011-2016) esse debate foi bastante rarefeito e, por vezes, ausente. Se considerado o documento base da PNDU (BRASIL, 2004), ainda 
que se considere a existência das desigualdades regionais, não há sequer uma menção às particularidades da região amazônica e ao desenvolvimento de políticas que atentem para a existência dessa diversidade urbana.

Podemos perceber que as políticas ambientais para a Amazônia no período entre 2004 e 2016 refletem o interesse nacional em seus valores históricos atualizados pela incorporação das demandas da cidadania (BECKER, 2010a, p. 143). Entende-se, contudo, que ainda prevaleceu o desenvolvimento numa estratégia territorial seletiva, na tentativa de combinar não apenas modelos diversos, como também opostos e conflitivos. Houve, por um momento curto da política territorial brasileira, uma comunicação entre os atores sociais para o estabelecimento de ações articuladas nos territórios.

Ainda é um grande desafio contribuir de forma a melhorar esse cenário na Amazônia, mas o primeiro passo é, certamente, aprender a não cometer erros do passado para se projetar novas perspectivas de planejamento para as cidades. É necessário, sobretudo, uma nova combinação de elementos que tenha o comprometimento com a justiça social e ambiental. Para isso, se torna de fundamental importância, como sugeriu Becker (2010), de pensar na integração interna no qual as cidades devem expandir os seus serviços para as sociedades das UCs e Terras indígenas, assim como aos centros dos assentamentos de reforma Agrária, possuem eixos de comunicação em rede que são fundamentais assegurar as articulações de cada eixo (BECKER, 2010).

Ainda que sob a pauta ideológica do desenvolvimento sustentável e na tentativa de conciliar lógicas historicamente divergentes, a experiência nacional de ordenamento territorial para a Amazônia entre 2010 e 2016 representou, no Brasil, o mais próximo da proposta internacional do trade-off entre crescimento e equilíbrio regional. A existência de uma política nacional de desenvolvimento regional articulada a uma política de desenvolvimento urbano constituiu avanços importantes, mas não deixou de reproduzir lógicas que reforçam a dinâmica capitalista, a exemplo do sistema híbrido de financiamento da moradia (Estado + mercado) e da dificuldade em reduzir desigualdades regionais em cidades historicamente afetadas por problemas ambientais ligados ao saneamento. Tal condição evidencia que a lógica da desigualdade ambiental é atravessada pela desigualdade socioeconômica, revelando problemas que estão para além das estratégias de governo.

\section{CONSIDERAÇÕES FINAIS}

Face aos modelos de diferentes políticas de ordenamento territorial na Amazônia, é perceptível a existência de políticas que, num primeiro momento, refletem o paradigma de integração nacional, porém sem uma preocupação com demandas que atendem ao bem-estar das populações locais ou ações efetivas de desenvolvimento sustentável. No período entre 1965 e 1988, as cidades são produzidas dentro de uma modelo de suporte aos projetos desenvolvimentistas baseado na exploração dos recursos naturais, porém pouco se aborda a respeito das cidades do ponto de vista da aplicação de ações efetivas de melhoria da qualidade de vida das populações. 
Com o fim do governo militar e após a constituição de 1988, foram construídos outros modelos de gestão do território pelo "desenvolvimento", âmbito da exploração dos recursos naturais, mas na tentativa de conciliar os interesses de sujeitos sociais antes excluídos ou negligenciados. Para Becker (2010a) a emergência de novas políticas públicas, sobretudo após a década de 1990, expressam uma alteração no conteúdo do interesse nacional, que incorpora à cidadania, envolvendo a conservação do meio ambiente, os direitos humanos e a democracia.

No período entre 2003 e 2016, apesar das questões relacionadas à sustentabilidade serem bem evidenciados e as políticas ambientais mais consistentes, o debate sobre o papel das cidades nas políticas de gestão ambiental na Amazônia ainda foram bastante rarefeitas e pouco conseguiram, de fato, atender demandas especificas dos territórios. No entanto, pela primeira vez houve a participação de movimentos sociais e representantes da sociedade civil na proposição de políticas alternativas na gestão dos espaços amazônicos. No que tange à problemática ambiental nas cidades, a PNDR e o PNDU foram importantes instrumentos para elaboração de estratégias em nível federal no enfrentamento de problemas relacionados ao risco ambiental e ao acesso a serviços de saneamento básico, além de temas relacionados à regulamentação fundiária. Além disso, as ações no âmbito do PMCMV para a oferta de residências às famílias mais pobres impactaram na melhoria das condições de habitabilidade, como acesso a redes de água e de esgotamento sanitário.

Percebe-se, então, que a lógica da compatibilidade entre crescimento econômico e equilíbrio regional é a proposta teórica fundamental de um ordenamento territorial de base sustentável. No Brasil, a experiência que melhor expressa a consistência desse tipo de política para as cidades amazônicas foi a que se deu entre 2001, tendo como marco a elaboração do Estatuto da Cidade, passando pelos Governos FHC e Lula até o ano em que acontece o impeachment da presidenta Dilma Rousseff, em 2016. Nesse período, que também é marcado por um crescimento econômico importante, os processos de conciliação de classe e de articulação entre sujeitos territoriais de interesses conflitivo se deu sob a mediação governamental, expressa por políticas nacionais de gestão do território. A lógica fundamental não é, por certo, a de ruptura ao modelo econômico, mas do estabelecimento de certos ajustes espaciais no desenvolvimento capitalista, muito mais ligada ao caminho de uma social-democracia de inspiração europeia.

O que se tem após 2016, entretanto, é um processo de mobilização das elites no sentido da desconstrução do modelo de gestão do território anteriormente produzida. Desse modo, ainda que se considere o modelo anterior (entre 2001 e 2016) como um modelo imperfeito de políticas ambientais e urbanas para a Amazônia, o que se desenha nos últimos anos é um retorno ao padrão anterior à constituição de 1988, portanto predatório e nocivo ao verdadeiro desenvolvimento ambiental e urbano com justiça social. 
Território e cidade na Amazônia:

Uma leitura a partir das políticas ambientais urbanas

\section{REFERÊNCIAS BIBLIOGRÁFICAS}

AQUINO, Maria José. Socioambientalismo e Novas Territorialidades: Complementaridades e Antagonismo em Desenvolver e Proteger. In: ROCHA, Gilberto de Miranda; MAGALHÃES, Sonia Barbosa; TEISSERENC, Pierre. Território de Desenvolvimento e Ações Públicas. Belém-PA: Edufpa, 2009. p. 318.

BARBOSA, Jorge Luiz. O ordenamento Territorial Urbano na era da acumulação globalizada. In: SANTOS, Milton et al. TERRITÓRIO, TERRITÓRIOS: ENSAIOS SOBRE O ORDENAMENTO TERRITORIAL. 2. ed. Rio de Janeiro: Dp\&a, 2006. p. 125-145.

BECKER, Bertha K. Novas territorialidades na Amazônia: desafio às políticas públicas. Boletim do Museu Paraense Emílio Goeldi. Ciências Humanas, v. 5, n. 1, p. 17-23, 2010.

BECKER, Bertha K. Revisão das políticas de ocupação da Amazônia: é possível identificar modelos para projetar cenários? Parcerias estratégicas, v. 6, n. 12, p. 135-159, 2010a.

BITOUN, Jan; MIRANDA, Lívia. Tipologia das cidades brasileiras. Observatório das Metrópolis-Letra Capital Editoras, Rio de Janeiro, 2009.

BOARETO, Renato. A política de mobilidade urbana e a construção de cidades sustentáveis. Revista dos Transportes Públicos-ANTP-Ano, v. 30, p. 31-2008, 2008.

BRASIL, MINISTÉRIO DAS CIDADES. Gasto Público em Saneamento Básico - 2013. Disponível em: https://www.mdr.gov.br/images/stories/ArquivosSNSA/Arquivos_PDF/gasto_publico_2013.pdf. Acesso em 31 de agosto de 2020.

CAMARGO, Luiz Henrique Ramos. ORDENAMENTO TERRITORIAL E COMPLEXIDADE: POR UMA REESTRUTURAÇÃO DO ESPAÇO SOCIAL. In: ALMEIDA, Flávio Gomes de; SOARES, Luiz Antônio Alves. ORDENAMENTO TERRITORIAL: COLETÂNIA DE TEXTOS COM DIFERENTES ABORDAGENS NO CONTEXTO BRASILEIRO. Rio de Janeiro: Bertrand, 2009. p. 21-60.

COSTA, Wanderley Messias da. O Estado e as políticas territoriais no Brasil. $3^{a}$ ed-São Paulo; Contexto, 1991.

DE MELlO-THÉRY, Neli Aparecida. Política (e ação) pública, território e o papel da Geografia. Revista da ANPEGE, v. 7, n. 01, p. 11-19, 2011.

FONSECA, Madalena Pires da. A política regional da União Europeia: uma utopia viável. E-topia: Revista Electrónica de Estudos sobre a Utopia, 2004, 2004.

IBGE. Censo demográfico 2010. Rio de Janeiro, 2010. disponível em: https://censo2010.ibge.gov.br/entorno/

INSTITUTO TRATA BRASIL. Benefício econômicos e sociais do saneamento no Brasil. Ex ante consultoria econômica, março de 2017

INSTITUTO TRATA BRASIL. Planilha do Ranking 2020. Disponível em: http://www.tratabrasil.org.br/images/estudos/itb/ranking_2020/Tabela_100_cidades_Ranking_Saneamento_4 .pdf. Acesso em 31 de agosto de 2020.

KOHLHEPP, Gerd. Conflitos de interesse no ordenamento territorial da Amazônia brasileira. Estudos avançados, v. 16, n. 45, p. 37-61, 2002. 
Território e cidade na Amazônia:

Uma leitura a partir das políticas ambientais urbanas

MARICATO, ERMÍNIA. O Ministério das Cidades e a política nacional de desenvolvimento urbano: Cidades brasileiras: a matriz patrimonialista. Políticas Sociais (IPEA), v. 12, p. 211-220, 2006.

MINISTÉRIO DAS CIDADES. Cadernos MCidades, $\mathrm{n}^{\circ}$ 1, 2004 - Política Nacional de Desenvolvimento Urbano. Disponível em: <www.cidades.gov.br/secretarias-nacionais/secretaria-de-habitação>Acesso em $31 / 08 / 2020$.

MINISTÉRIO DAS CIDADES. Secretaria Nacional de Habitação Departamento de Desenvolvimento Institucional e Cooperação Técnica. Empreendimentos do Programa Minha Casa, Minha Vida - Faixa 1 - Modalidade Empresas. Planilha: Excel, 2016

MORAES, Antonio Carlos Robert. Território e história no Brasil. São Paulo: Annablume, 2005.

NOGUEIRA, Ana Cláudia Fernandes; SANSON, Fábio; PESSOA, Karen. A expansão urbana e demográfica da cidade de Manaus e seus impactos ambientais. In: XIII SIMPÓSIO BRASILEIRO DE SENSORIAMENTO REMOTO, 21-26., 2007, Florianópolis. Anais... Florianópolis: Brasil, 2007. p. 5427 5434.

PECCATIEllo, Ana Flávia Oliveira. Políticas públicas ambientais no Brasil: da administração dos recursos naturais (1930) à criação do Sistema Nacional de Unidades de Conservação (2000). Desenvolvimento e Meio ambientes, v. 24, 2011.

PLANALTO. Presidência da República Casa Civil Subchefia para Assuntos Jurídicos: lei no 10.257, de 10 de julho de 2001. LEI No 10.257, DE 10 DE JULHO DE 2001. 2020. Disponível em: http://www.planalto.gov.br/ccivil_03/leis/leis_2001/110257.htm. Acesso em: 08 ago. 2020.

PORTO, Manuel. O ordenamento do território face aos desafios da competitividade. 1996.

RUCKERT, Aldomar Arnaldo. Usos do território e políticas territoriais contemporâneas: alguns cenários no Brasil, União Europeia e Mercosul. Revista de Geopolítica, v. 1, n. 1, p. 17-32, 2016.

SILVA Lucia; TRAVASSOS, Luciana. Problemas ambientais urbanos: desafios para a elaboração de políticas públicas integradas. Cadernos Metrópole. 19 (2008).

SILVA, SIMONE AFFONSO DA; BORGES, LUCIANA RIÇA MOURÃO. As Políticas de Ordenamento Territorial e de Planejamento Regional no Brasil nos Anos 1990 e 2000: Um Breve Estudo sobre os Enids, a PNDR, o PAC e os Territórios da Cidadania. As Escalas de Gestão das Políticas Territoriais, p. 1354-1367, 2014. 